\title{
XXIV. An account of a method of dividing astronomical and other instruments, by ocular inspection; in which the usual tools for graduating are not employed; the whole operation being so contrived, that no error can occur but what is chargeable to vision, when assisted by the best optical means of viewing and measuring minute quantities
}

Mr. Edward Troughton

To cite this article: Mr. Edward Troughton (1809) XXIV. An account of a method of dividing astronomical and other instruments, by ocular inspection; in which the usual tools for graduating are not employed; the whole operation being so contrived, that no error can occur but what is chargeable to vision, when assisted by the best optical means of viewing and measuring minute quantities, Philosophical Magazine Series 1, 34:137, 163-177, DOI: $10.1080 / 14786440908562944$

To link to this article: http://dx.doi.org/10.1080/14786440908562944 
produces the smallest effect of all, and does but little good or harm.

Secondly, If it enters the body by a conductor in contact, and has to escape in the manner of perspiration, a strong effect is produced; and this may be confined to one place, and of course be rendered more powerful by the attracting points.

Thirdly, An effect equally strong, but quite the reverse of the last, will be produced by placing the patient insulated in contact with the negative conductor, and in a damp atmosphere*. By this mode of operating the effect takes place all over his body : but if, instead of this, you bring a wet sponge, connected with the earth, near the part affected, it will be confined to that place.

In the former case the electricity acts by increasing the natural perspirations, but in the latter, by strongly checking it, or occasioning an absorption of moisture.

I think the failures in medical electricity have been where this last application was wanted ; for electricity alone, applied in any way, has a tendency to dissipate moisture; which effect the last method enables you to reverse.

Paddington, Aug. 3, 1809.

XXIV. An Account of a Method of dividing astronomical and other Instruments, by ocular Inspection; in which the usual Tools for graduating are not employed; the whole Operation being so contrived, that no Error can occur but what is chargeable to Vision, when assisted by the lest optical Means of viewing and measuring minute Quantities. By Mr. EdWard Trovghton.

[Concluded from p. 95.]

$\mathbf{R}_{\text {especting the angular value of the numbers in these }}$ tables, it may be worth mentioning, that it is not of the least importance; 100 of them being comprised in one revolution of the micrometer screw; and, in the instance before me, 5.6 of them made no more than a second. It is not pretended that one of these parts was seen beyond a doubt, being scarcely $\frac{1}{5000}$ th of an inch, much less the tenths, as exhibited in the tables; but, as they were visible upon the micrometer heads, it was judged best to take them into the account.

* A damp atmosphere is easily produced by using a pan of boiling water; but in this case the machine, that it may be kept dry, should be in another room, and the conductor should pass, insulated, through the wall to the patient. 
Having now completed the two first sections of my method of dividing; namely, the first, which consists of making 256 small round dots; and the second, in finding the errors of those dots, and forming them into a table; - I come now to the third and last part, which consists in using the erroneous dots in comparison with the tabulated errors, so as ultimately to make from them the true divisions.

It will here be necessary to complete the description of the remaining part of the apparatus. And first, a little instrument which I denominate a subdividing sector presents itself to notice. From all that has hitherto been said, it must have been supposed that the roller itself will point out, upon the limb of the instrument to be divided, spaces corresponding to others previously divided upon itself, as was done in setting off the 256 points : but, to obviate the difficulty of dividing the roller with sufficient exactness, recourse was had to this sector; which also serves the equally important purpose of reducing the bisectional points to the usual division of the circle. This sector is represented in half dimensions by Fig. 5 : it is formed of thin brass, and centred upon the axis at $A$, in contact with the upper surface of the roller : it is eapable of being moved round by hand; but, by its friction upon the axis and its pressure upon the roller, it is sufficiently prevented from being disturbed by accident. An internal frame B B, to which the arc $\mathrm{C} \mathrm{C}$ is attached, moves freely in the outer one, and by a spring $D$ is pushed outwards, while the screw $E$, whose point touches the frame $B$, confines the arc to its proper radius. The arc of this sector is of about four times greater radius than the roller, and upon it are divided the spaces which must be transferred to the instrument, as represented on a magnified scale by Fig. 4 . Now, the angle of one of the spaces of the circle will be measured by sixteen times its angular value upon the sectorial arc, or $22^{\circ} 30^{\prime}$; but this does not represent any number of equal parts upon the instrument, whose subdivisions are to be $5^{\prime}$ each ; for $\frac{1^{\circ} 24^{\prime} 22^{\prime \prime} 5}{5}$ is exactly $16 \frac{7}{8}$ ths, therefore so many divisions are exactly equal to a mean space between the dots whose errors have been tabulated. Let, therefore, the arc of the sector be divided into 16 spaces of $1^{\circ} 20^{\prime}$ each, and let a similar space at each end be subdivided into eight parts of $10^{\prime}$ each, as in Fig. 4 ; we shall then have a scale which furnishes the means for making the true divisions, and an immediate examination at every bisectional point.

I have 
I have always divided the sector from the engine, because that is the readiest method, and inferior to none in point of accuracy, where the radius is very short; but, as it is more liable than any other to centrical error, the adjustment of the arc by the screw $E$ becomes necessary : by that adjustment, also, any undue run in the action of the roller may be reduced to an insensible quantity *.

When the utmost degree of accuracy is required, I give the preference to dividing by lines, because they are made with a less forcible effort than dots are; and also because, if any small defect in the contexture of the metal causes the cutter to deviate, it will, after passing the defective part, proceed again in its proper course, and a partial crookedness in the line will be the only consequence; whereas a dot, under similar circumstances, would be altogether displaced. But, on the other hand, where accuracy has been out of the question, and only neatness required, I have used dots; and I have done so, because I know that when a dot and the wire which is to bisect it are in due proportion to each other, (the wire covering about two-thirds of the dot,) the nicest comparison possible may be obtained. It may be further observed, that division by lines is complete in itself; whereas that by dots requires lines to distinguish their value.

On the upper side of Fig. 1. is represented the apparatus for cutting the divisions. It consists of three pieces $\mathrm{JK} \mathrm{L}$, jointed together so as to give to the cutter an easy motion for drawing lines directly radiating from the centre, but inflexible with respect to lateral pressure; $d d$ are its handles. The culting point is hidden below the microscope $H$; it is of a conical form, and were it used as a dotting point, it would make a puncture of an elliptical shape, whose longer diameter would point towards the centre. This beautiful contrivance, now well known, we owe to the ingenuity of the late $\mathrm{Mr}$. Hindley of York; it was borrowed by $\mathrm{Mr}$. Ramsdent, and applied with the best effect to his dividing engine.

It might have been mentioned sooner, that in the instance which I have selected as an example of my dividing, the operation took place when the season of the year, and the smoke of London, had reduced the day to scarcely six hours of effective light; and rather than confine my labours

* See note page 166 .

+ This I learned from that most accurate artist Mr. John Stancliffe, who was himself apprentice to Hindley. 
within such narrow limits, I determined to shut out the day-light altogether. Fig. 7. shows the construction of the lanterns which I used. A very small wick gave sufficient light, when kept from diverging by a convex lens; while the inclining nossel was directed down exactly upon the part looked at, and the light, having also passed through a thin slice of ivory, was divested of all glare. I enter into this description, because, I think, I never eaw my work better, nor entirely to so much advantage as in this instance; owing, perbaps, to the surrounding darkness allowing the pupil of the eye to keep itself more expanded, than when indirect rays are suffered to enter it. The heat from a pair of these lanterns was very inconsiderable, and chiefly conducted along with the smoke up the reclining chimney.

Previous to cutting the divisions, the parts now described myst be adjusted. The cutting apparatus must be placed with the dividing point exactly at the place where the first line is intended to be drawn, and clamped, so that the adjusting screw may be able to run it through a whole interval. The microscope $\mathrm{H}$ must be firmly fixed by its twa pillars $b b$ to the main frame, with its micrometer head at zero; and with its only wire in the line of the radius, bisecting the first of the $z 56$ dots. And it should be observed, that the cutting frame and this must not vary respecting each other, during the time that the divisions are cut; for any motion that took place in either would go undiminished to the account of error. The microscope $I$ is also fastened to the main frame ; but it is only required to keep its position unvaried, while the divisions of the sector pass once under its notice; for it must have its wire adjusted afresh to these divisions at every distinct. course. The microscope I has two wires, crossing each other at an angle of about $40^{\circ}$; and these are to be placed so as to make equal angles with the divisions of the sector, which are not dots, but lines. The sectorial arc must also be adjusted to its proper radius by the screw E, Fig. 5 ; $i . e$, while the main frame has been carried along the circle through a mean interval shown by $\mathrm{H}$, the sector must have moved through exactly $16 \frac{7}{8}$ ths of its divisions, as indicated by $I^{*}$.

Things

* For the sake of simplicity, the account of the propess is carried on as if the roller measured the mean interval without error: But it was said (page 84) that the roller, in a continued motion quite round the circle, would in some part of its course err by $30^{\prime \prime}$ or more; therefore, when that is the case, an extreme run of the roller cannot agree with a mean interval of the circle nearer than $\frac{30^{\prime \prime}}{128}=0^{\prime \prime} \cdot 28$; and most probably this kind of error will 
Things being in this position; after having given the parts time to settle, and having also sufficiently proved the permanence of the micrometer $\mathrm{H}$ and the cutting frame with respect to each other, the first division may be made; then, by means of the screw for slow motion, carry the apparatus forward, until the next line upon the sector comes to the cross wires of $I$; you then cut another division, and thus proceed until the 16 th division is cut, $=1^{\circ} 20^{\prime}$ : Now the apparalus wants to be carried further, to the amount of $\frac{7}{8}$ ths of a division, before an interval is complete; but at this last point no division is to be made; we are here only to compare the division on the sector with the corresponding dot upon the instrument. This interval, however, upon the circle will not be exactly measured by the corresponding line of the sector, which has been adjusted to the mean interval, for the situation of the dot 10.4 is too far back, as appears by the table of real errors, by -4.8 divisions of the micrometer head. The range of the screw for slow motion must now be restored, the cross wires of II set back to -4.8 divisions, and the sector moved back by hand, but not to the division 0 where it began before; for, as it left off in the first interval at $\frac{7}{8}$ ths of a division, it has to go forwards $\frac{1}{8}$ th more before it will arrive at the spot where the 17 th division of the instrument $1^{\circ} 25^{\prime}$ is to be made, so that in this second course it must begin at $\frac{1}{6}$ th short of 0 . Go through this interval as before, making a division upon the circle at every one of the 16 great divisions of the sector; and $\mathrm{H}$ should now reach the third dot, allowing for a tabular error of -10.2 when the division $\frac{\sigma}{8}$ ths of the sector reaches the cross wires of I. It would be tedious to lead the reader through all the varitty of the sector, which consists of eight courses; and it may be sufficient to observe, that at the commencement of every course, it must be put back to the same fraction of a division which terminated its former one; and that the wire of the micrometer $\mathrm{H}$ must always be set to the tabular error belonging to every dot, when we end one interval and begin another. The eight courses of the sector will have carried us through $\frac{1}{32} \mathrm{~d}$ part of the circle, $11^{\circ} 15^{\prime}$, and during this time, the roller will have proceeded through half a revolution; for its close contact with the limb of the circle does not allow

on some intervals amount to double that quantity. It therefore becomes matter of prudent precaution to examine every interval previous to making the divisions; and, where necessary, to adjust the sector, so that its are may exactly measure the corresponding interval as corrected by the tabulited errors. 
it to return with the sector when the latter is set back at every course. Having in this manner proceeded, from one interval to another, through the whole circle, the micrometer at last will be found with its wire, at zero, on the dot from which it set out; and the sector, with its 16 th division, coinciding with the wires of its microscope.

Having now given a faithful detail of every part of the process of dividing this circle, I wish to remind the reader that, by verification and correction at every interval, any erroneous action of the roller is prevented from extending its influence to any distant interval. It will be further observed, that the subdividing sector magnifies the work; that by means of its adjustable arc, it makes the run of the roller measure its corresponding intervals upon the circle; and, without foreign aid, furnishes the means of reducing the bisectional intervals to the usual division of the circle. Furthermore, the motion of the wire of the micrometer $\mathrm{H}$, according to the divisions of its head and corresponding table of errors, furnishes the means of prosecuting the work with nearly the same certainty of success, as could have happened, had the 256 points been (which in practice is quite impossible) in their true places.

Now, the whole of my method of dividing being performed by taking short measures with instruments which cannot themselves err in any sensible degree, and, inasmuch as those measures are taken, not by the hand, but by vision, and the whole performed by only looking at the work, the eye must be charged with all the errors that are committed until we come to cut the divisions; and, as in this last operation the hand has no more to do than to guide an apparatus so perfect in itself, that it cannot be easily made to deviate from its proper course, I would wish to distinguish it from the other methods by denominating it, dividing by the eye*.

The

* I must here remark, that Smeaton has represented the greatest degree of accuracy that can be derived from vision, in judging of the coincidence of two lines at $\frac{1}{4000}$ th part of an inch. From this it may fairly be inferred, that he had not cultivated the power of the sight, as he had done that of the touch; the latter of which, with that ability which appeared in all his works, he rendered sensible to the ${ }_{60600}$ th part of an inch. Were materials infinitely hard, no bourds could be set to the precision of contact; but saking things as they are, the different degrees of hardness in matter, may be considered as a kind of magnifying power to the touch, which may not unaptly be compared with the assistance which the eye receives from glasses. It is now quite common to divide the seaman's sextant to $10^{\prime \prime}$, and a good eye will estimate the half of it; which, on an eight-inch radius, is scarcely roooth of an inch. This quantity, small as it is, is rendered visible by a glass of one inch focal length; and such is the certainty with which these 
The number of persons at all capable of dividing originally have hitherto been very few ; the practice of it being so limited, that, in less than twice seven years, a man could hardly hope to become a workman in this most diffcult art. How far I shall be considered as having surmounted these difficulties, I know not; but if, by the method here revealed, I have not rendered original dividing almost equally easy with what copying was before, I have spent much labour, time, and thought in vain. Thave no doubt indeed, that any careful workman who can divide in common, and has the ability to construet an astronomical instrument, will, by following the steps bere marked out, be able to divide it, the first time he tries, better than the most experienced workman, by any former method.

If, instead of subdividing with the roller, the same thing be performed with the screw, it will not give to dividing by the eye any very distinctive character: I have practised this on arcs of circles with success, the edge being slightly racked, the screw carrying forward an index with the requisite apparatus, and having a divided micrometer head; the latter answers to the subdividing sector, and, being used with a corresponding table of errors, forms the means of correcting the primitive points; but the roller furnishes a more delicate action, and is by far more satisfactory and expeditious.

It is known to many that the six-feet circle, which I am now at work upon for our Royal Observatory, is to be divided upon a broad edge, or upon a surface at right angles to the tisual plane of division: the only alterations, which will on that account be required, are, that the roller must act upon that plane which is usually divided upon; which roller, being elevated or depressed, may be adjusted to the commensurate radius without being made conical, as was necessary in the other case. The apparatus, similar to the other, must here be fixed immoveable to the frame which

Giantitics are seen, that a seaman will sometimes complain that two pair of these lines will coincide at the same time; and that may happen, and yet no division of his instrument err, by more than $\overrightarrow{260^{\circ} \overline{0}}$ th part of an inch. All this is applicable to judging of the coincidence of lines with each other, and furnishes not the most favourable display of the accuracy of vision. But with the microscopes here described, where the wire bisects the image of a dot, or a cross wire is made to intersect the inage of a line, by an eye practised in sucli matters, a coincidence rnay wadoubtedly be ascertained to ${ }_{5}$ sto $^{\circ} 0^{\text {th }}$ part of an inch. I am of opinion that as small a quantity may be rendered visible to the eye, as can by contact be made sensible to the touch; but whether Mr. Smeaton's $\frac{1}{60} \frac{1}{60}$ and $m y_{50000}^{\frac{1}{500}}$ be wot the same thing, I will not determine; the difference between them, however, is what he would no more have pretended to feel, than I dare pretend to see. 
supports the circle; its position must be at the vertex, where also I must have my station; and the instrumes $t$ itself must be turned around its axis, in its proper vertical position, as the work proceeds. The above may suffice, for the present, to gratify those who feel themselves interested upon a subject which will be better understood, if $\mathbf{I}$ should hereafter have the honour of laying before the Royal Society a particular description of the instrument here alluded to; a task which I mean to undertake, when, after heing fixed in the place-designed for it, which I hope will be effected at no very distant period, it shall be found completely to answer the purposes intended.

Should it be required to divide a circle according to the centesimal division of the quadrant, as now recommended and used in France, we shall have no difficulty. The $100^{\circ}$ of the quadrant may be conveniently subdivided into 10 each, making 4000 divisions in the whole round. The 256 bisectional intervals, the two tables of errors, and the manner of proceeding and acting upon them, will be exactly the same as before, until we come to cut the divisions; and for this purpose we must have another line divided upon the sector. For $\frac{1}{00}$ th part of the circle being equal to $5^{\prime} \cdot 4$ of the usual angular measure $\frac{1^{\circ} 24^{\prime} 22^{\prime \prime} \cdot 5}{5^{\prime \circ} \cdot 4}=15$ s ths divisions; and just so many will be equivalent to one of the intervals of the circle. The value of one of the great divisions of the sector will be $1^{\circ} 26^{\prime} 24^{\prime \prime}$, and that of the $\frac{1}{8}$ th parts, which are to be annexed to the right and left as before, will be $10^{\prime} 48^{\prime \prime}$, therefore divisible by the engine. Should any astronomer choose to have both graduations upon his instrument, the additional cost would be a mere trifle, provided both were done at the same time.

It must already have been anticipated, that dividing by the eye is equally applicable to straight lines as it is to circles. An apparatus for this purpose should consist of a bar of brass, three quarters of an inch thick, and not less than three inches broad; six feet may do very well for the length; it may be laid upon a deal plank strengthened by another plank screwed tdgewise on its lower surface. The bar should be planed, on both its edges and on its surface, with the greatest exactness; and it will be better, if it has a narrow slip of silver, inlaid through its whole length, for receiving the dots. An apparatus nearly similar to the other should slide along its surface, carrying a roller, whose circumference is 12.8 inches, and turned a little conical for the sake of adjustment. The roller may be divided into 
32 parts, each of which when transferred to the bar will give intervals of 0.4 of an inch each : the angle of the subdividing sector should of course be $11^{\circ} 15^{\prime}$, and subdivided into four parts, which will divide the inch into tenths: the surface may also receive other lines, with subdivisions suited to the different purposes for which it may be wanted. The revolutions of the roller and its $-\frac{1}{3} \pi$ parts must be dotted upon the bar; taking care, by sizing the roller, to come as near the true standard measure as possible: when this is done, compare the extent of the greater bisectional number that is contained in the length; $i . e .128$ intervals of 51.2 inches, with the standard measure; noting the difference as indicated by the micrometer heads: the examination and construction of the table of errors may then be conducted just as was done for the circle.

Being now ready for the performance of its work, the scale to be divided must be laid alongside of the bar, and the true divisions must be cut upon it by an appeal, as before, to the erroneous dots on the bar, corrected by a corresponding table of errors. The apparatus, remaining entire in the possession of the workman, with its primitive dots, the table of errors, \&c., is ready for dividing another standard, which will be precisely similar to others that have been, or may be, divided from it. It may be considered, indeed, as a kind of engine; and, as it is not vitiated by the coarse operation of racking with a screw, but performed by only looking at the work, the method will command about three times the accuracy that can be derived from the ususl straight-line dividing engine. Should it he asked, if an engine thus appointed would succeed for dividing circles? $I$ answer, Yes; but I would not recommend it; because, beyond a certain extent of radius, it is not necessary; for the errors, which would be introduced into the work by the violence of racking a large wheel, are sufficiently reduced by the compararive shortness of the radius of such instruments as we divide by that method: and, what is still more to the purpose, the dividing engine is four times more expeditious, and bears rough usage better. I cannot quit the subject of dividing straight lines without observing, that I never had my apparatus complete. The standard which I made for sir George Shuckburg Evelyn in 1796, was done by a mere make-shift contrivance, upon the principle of dividing by the eye; how I succeeded may be seen in Sir George's papers on Weights and Measures (Philosophical Transactions for 1798). I made a second, some years after, for professor Pictet of Geneva, which 
which became the subject of comparison with the new measure of France, before the National Institute ; and their report, drawn up by Mr. Pictet, has been ably re-stated and corrected by Dr. Young, as published in the Journals of the Royal Institution. I made a third for the magistrates of Aberdeen. I notice the two latter, principally to give myself an opportunity of saying that, if those three scales were to be compared together, notwithstanding they were divided at distant periods of time, and at different seasons of the year, they would be found to agree with each other, as nearly as the different parts of the same scale agree.

I hope I may here be allowed to allude to an inadvertency which has been committed in the paper mentioned above; and which sir George intended to have corrected, had he lived to conclude his useful endeavours to harmonize the discordant weights and measures of this country. The instruments which he has brought into comparison are, his own five-feet standard measure and equatorial; general Roy's forty-two inch scale; the standard of $\mathrm{Mr}$. Aubert; and that of the Royal Society. The inadvertency is this: in his equatorial, and the standard of the Royal Society, he has charged the error of the most erroneous extent, when compared with the mean extent, alike to both divisions; i.e. he has supposed one of the divisions, which bound the erroneous extent, to be too much to the right, and the other too much to the left, and that by equal quantities. This is certainly a good-natured way of stating the errors of work; and perhaps not unjustly so, where the worst part has been selected; but in the other three instances, namely, in general "Roy's, Mr. Aubert's, and his own standard, he has charged the whole error of the most erroneous extent to one of the bounding lines.

I was well confirmed in my high opinion of the general accuracy of Bird's dividing, when, last winter*, I measured the chords of many arcs of the Greenwich quadrant: that instrument has indeed suffered both from a change in its figure, and from the wearing of its centre; but the graduation, cousidering the time when it was done, I found to be very good. Sir George in his paper upon the Equatorial (Philosophical Transactions for 1793), after some compliments paid to the divider of his instrument, says, "The late Mr. John Bird seems to have admitted a probable discrepancy in the divisions of his eight-feet quadrant

* This paper was written in June 1808. 
amounting to $3^{\prime \prime} ; "$ and he refers to Bird on the construction of the Greenwich quadrant. This quantity being three times as great as any errors that I met with, I was lately induced to inquire how the matter stood. Bird, in the paper referred to, says, "In dividing this instrument I never met with an inequality that exceeded one second. I will suppose that in the 90 arch this error lay towards the left hand, and in the 96 arch that it lay towards the right, it will cause a difference between the two arches of two seconds; and if an error of one second be allowed to the observer in reading off his observation, the whole amount is no more than three seconds, which is agreeable to what I have heard, \&c." Sir George's examination of his own equatorial furnishes me with the means of a direct comparison: in his account of the declination circle, we find an error $+2^{\prime \prime} \cdot 35$, and another $-1^{\prime \prime} \cdot 5$; to these add an error of half a second in each, for reading off, which sir George also admits; we shall then have a discrepancy of $4^{\prime \prime} \cdot 85$; but as the errors of reading off are not errors of division, let them be discharged from both, and the errors will then stand,--for the quadrant $2^{\prime \prime}$, and for the circle $3^{\prime \prime} \cdot 85$. As the radius of the former, however, is four times greater than that of the latter, it will appear, by this mode of trial, that the equatorial is rather more than rwice as accurately divided as the quadrant. In doing justice to Bird in this instance, I have only done as I would be done by ; for, should any future writer set me back a century on the chronological scale of progressive improvement, I hope some one will be found to resture me to my proper niche. I now subjoin a re-statement of the greatest error of each of the instruments that are brought into comparison by sir George, after having reduced them all by one rule; viz. allowing each of the two points which bound the most erroneous extent to divide the apparent error equally between them. They are expressed in parts of an inch, and follow. each other in the order of their accuracy.

Sir George Shuckburg's 5-feet standard ·000165 General Roy's scale of 42 inches - - $\cdot 000240$

Sir George's equatorial, 2-feet radius - .000273

The Greenwich quadrant, 8 feet radius -, 000465

Mr. Aubert's standard, 5 feet long - _ - 000700

The Royal Society's standard, 92 inches long* • 000795

For the justness of the above statement I consider my name as pledged; requesting the permission to say, that if

* This is the same which Mr. Bird used in dividing his eight-feet mural quadrants, and was preseated to the Royal Society by Bird's executors. 
on the result of each respective examination, as here presented, there could have been more than one opinion, it would not have appeared here. I am further prompted to add, that the above comparative view presents one circumstance to our notice, which cannot do less than gratify every individual who is at all conversant in there matters; I mean, the high rank which general Roy's scale takes in the list; that scale having been made the agent in measuring the base line of our national trigonometrical survey.

To return, finally, to the dividing of circles; I must state, as matter of precaution, that great care should be taken during the turning of the outer edge, to have the circle of the same temperature; for one part may be expanded by heat, or contracted by cold, so much more than another, as to cause the numbers in the tables of errors to be inconveniently large. A night is not more than suffcient for allowing the whole to take the same temperature, after having been handled by the workmen; and the finishing touch should be given within a short space of time. But, if the effects of temperature are to be regarded in turning a circle, it is of tenfold more importance to attend to this circumstance, while the examination of the larger arcs of the instrument is carried on ; for it is absolurely necessary that, during this time, the whole circle should be of the same heat exactly. Few workmen are sufficiently aware of this: they generally suppose the expansion of metals to be a trifle which need not be regarded in practice; and wonder how the parts of a circle can be differently heated without taking pains to make it so. One degree of Fahrenheit's thermometer indicates so small a portion of heat that, in such places as workmen are usually obliged to do their business in, it is not very easy to have three thermometers attached to different parts of a large instrument, showing an equality of temperature within that quantity : yet so necessary is correctness in this respect, that if a circle has the vertex one degree warmer than its opposite, and if this difference of temperature be regularly distributed from top to bottom, the uper semi-circle will actually exceed the lower by $2^{\prime \prime}$ : and, if such should happen to be the case while the examination of the first dot of the third quadrant is made, the regularity of the whole operation would thereby be destroyed.

It may not be improper to remark, that dividing by the eye daes not require a more expensive apparatus than the operation of dividing by hand; and, indeed, less so when the scale of inches is deemed necessary. The method by adjustment 
adjustment is still more expensive, requiring whatever tools Bird's method requires, and, in addition to these, a frame and microscopes, somewhat similar to those for dividing by the eye.

It is somewhat more difficult to give a comparative estimate of the time which the different methods of dividing require. I know that thirteen days of eight hours each are well employed in dividing such a circle by my method; about fifty-two days would be consumed in doing the same thing by Bird's method; and I think I cannot err much when I state the method by adjustment, supposing every dot to be tried, and that two-thirds of them want adjusting, to require about one hundred and fifty of such days.

The oconomy of time (setting aside the decided means of accuracy) which the above estimate of its application offers to view, will, I think, be considered of no little moment. By the rising artist who may aspire at excellence, it will at least, and I should hope, with gratitude, be felt in the abbreviation of his labours. To me, indeed, the means of effecting this became indispensable; and it has not been without a sufficient sense of its necessity, that I have been urged to the progressive improvement and completion of these means, as now described. It it but little that a man can perform with his own hands alone; nor is it on all occasions, even in frames of firmer texture than my own, that he can decisively command their adequate, unerring, use. And I must confess that I never could reconcile it to what I hold as due to myself, as well as to a solicitous regard for the most accurate cultivation of the science of astronomy, to commit to others an operation requiring such various and delicate attentions, as the division of my instruments.

That my attentions on this bead have not failed to procure for me the notice and patronage of men whose approbation makes, with me, no inconsiderable part of my reward, I have to reflect on with gratitude and pleasure: and as I look with confidence to the continuance of that patronage so long as the powers of execution shall give me the inclination to solicit it, I cannot entertain a motive which might go to extinguish the more liberal wish of pointing out to future ingenuity a shorter road to eminence ; sufficiently gratified by the idea of having, in the present communication, contributed to facilitate the operations, and to aid the progress of art (as far as the limited powers of vision will admit) towards the point of perfection. 
Table of apparent Error's.

\begin{tabular}{|c|c|c|c|c|c|c|c|c|c|}
\hline $\begin{array}{l}\text { Name of } \\
\text { the Dof. }\end{array}$ & $\mid \begin{array}{c}\text { First } \\
\text { |quadrant. }\end{array}$ & $\mid \begin{array}{c}\text { second } \\
\text { Quradrant. }\end{array}$ & $\begin{array}{c}\text { Third } \\
\text { Quadrant. }\end{array}$ & 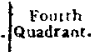 & $\| \begin{array}{c}F 12 s \tau \\
20 \text { adiant }\end{array}$ & $\int \begin{array}{c}\text { second } \\
\text { Quadrant. }\end{array}$ & | $\begin{array}{c}\text { Th:ud } \\
\text { Quadrant. }\end{array}$ & $\int \begin{array}{l}\text { Fouth } \\
\text { Wuatran' }\end{array}$ & $\begin{array}{l}\text { Yume of } \\
\text { the Dor. }\end{array}$ \\
\hline $\begin{array}{c}0 \\
0 \cdot 9\end{array}$ & 0 & +12.2 & -6.9 & $9+17 \cdot 9$ & +4.6 & $6+17 \cdot 1$ & $\rightarrow 4.4$ & $4+17 \cdot 3$ & $\stackrel{0}{1.4}$ \\
\hline 45.0 & $-21 \cdot 3$ & -8.9 & $16 \cdot 7$ & $-29 \cdot 6$ & $\|-5.2$ & $-9 \cdot 7$ & $8 \cdot 9$ & $9 \mid-6.4$ & $4 \cdot 2$ \\
\hline $22 \cdot 5$ & $1 \cdot 6$ & $2 \cdot 2$ & $1 \cdot 0$ & $2 \cdot 7$ & 0.0 & 3.8 & 1.0 & $4 \cdot 7$ & 7.0 \\
\hline $67 \cdot 5$ & $+1 \cdot 0$ & $+15 \cdot 6$ & $0-0$ & $+13 \cdot 7$ & $1+1 \cdot 0$ & +3.5 & $5 \cdot 1$ & $5 \cdot 5$ & $9 \cdot 8$ \\
\hline $11 \cdot 2$ & $-16 \cdot 6$ & -20.2 & $22 \cdot 6$ & -30.8 & -5.5 & -1.6 & 0.0 & $\mid+1 \cdot 2$ & $12 \cdot 7$ \\
\hline $33 \cdot 7$ & 4.0 & 4.2 & 18.2 & 23.1 & $7 \cdot 6$ & $7 \cdot 6$ & $4 \cdot 2$ & -2.3 & $15 \cdot 5$ \\
\hline 56.2 & 16.9 & $22 \cdot 2$ & $17 \cdot 0$ & $\varepsilon 2 \cdot 7$ & $9 \cdot 4$ & $3 \cdot 9$ & 0.0 & 5.3 & $18 \cdot 3$ \\
\hline $78-7$ & $30 \cdot 8$ & $16 \cdot 6$ & $31 \cdot 3$ & $30 \cdot 3$ & $+1 \cdot 1$ & $+12-1$ & +4.2 & +43 & $21 \cdot 1$ \\
\hline $5 \cdot 6$ & $2 \cdot 7$ & $8 \cdot 6$ & 41 & $10 \cdot 1$ & 12.3 & 0.9 & 6.2 & J4.4 & $23 \cdot 9$ \\
\hline 16.9 & 11.5 & $11 \cdot 3$ & $11 \cdot 2$ & $16 \cdot 1$ & -5.7 & -6.2 & $1 \cdot 1$ & $-11 \cdot 2$ & $56 \cdot 7$ \\
\hline 98.1 & $9 \cdot 0$ & $7 \cdot 4$ & $5 \cdot 8$ & $14 \cdot 3$ & +1.5 & $3 \cdot 5$ & -6.3 & & $89-5$ \\
\hline $39 \cdot 4$ & $9 \cdot 3$ & $8 \cdot 2$ & $5 \cdot 8$ & $13 \cdot 1$ & 0.0 & $7 \cdot 0$ & $7 \cdot 7$ & +1.4 & $32 \cdot 3$ \\
\hline $50 \cdot 6$ & $4-2$ & $6 \cdot 6$ & $8 \cdot 2$ & $4 \cdot 4$ & $1 \cdot 5$ & +9.0 & +3.0 & $4 \cdot 3$ & $35 \cdot 2$ \\
\hline 61.9 & $4 \cdot 3$ & $8 \cdot 4$ & $12 \cdot 5$ & $4 \cdot 4$ & -8.6 & -5.9 & -2.0 & -6.7 & 98.0 \\
\hline $75 \cdot 1$ & $7 \cdot 6$ & $10 \cdot 0$ & $13-6$ & $9 \cdot 7$ & $8 \cdot 9$ & +2.7 & 4.9 & 1.5 & 40.8 \\
\hline $84 \cdot 4$ & $18 \cdot 0$ & +6.0 & $16 \cdot 3$ & $7 \cdot 1$ & +4.0 & 3.1 & $3 \cdot 5$ & $+1 \cdot 0$ & $43 \cdot 6$ \\
\hline 2.8 & $3 \cdot 4$ & -7.5 & $8-9$ & $2 \cdot 1$ & $13 \cdot 5$ & 10.5 & $+16 \cdot 0$ & 14.9 & $46 \cdot 4$ \\
\hline $8 \cdot 4$ & 0.0 & $5 \cdot 0$ & $4 \cdot 6$ & $5 \cdot 7$ & $2 \cdot 1$ & 0.0 & $1 \cdot 7$ & -3.5 & $49 \cdot 2$ \\
\hline $14 \cdot 1$ & $6 \cdot 6$ & $8 \cdot 2$ & $5 \cdot 6$ & $4 \cdot 8$ & -5.0 & $-10 \cdot 7$ & -2.9 & 1.5 & $52 \cdot 0$ \\
\hline $19 \cdot 7$ & $1 \cdot 6$ & $2 \cdot 4$ & +1.0 & $2 \cdot 5$ & 4.2 & $7 \cdot 9$ & $2 \cdot 2$ & $7 \cdot 2$ & 54.8 \\
\hline $25 \cdot 8$ & $3 \cdot 7$ & $8 \cdot 2$ & -29 & $2 \cdot 5$ & $4 \cdot 0$ & 3.0 & 2.5 & $1 \cdot 0$ & $57 \cdot 7$ \\
\hline $30-9$ & +2.4 & $7 \cdot 1$ & $7 \cdot 0$ & 0.0 & $7 \cdot 3$ & +6.2 & $6 \cdot 1$ & 1.5 & $60-5$ \\
\hline $36 \cdot 6$ & -5.9 & +1.0 & $2 \cdot 5$ & 1.5 & $3 \cdot 2$ & $|-10 \cdot 1|$ & $5 \cdot 6$ & $12 \cdot 7$ & $63 \cdot 6$ \\
\hline $42 \cdot 2$ & +3.1 & $1 \cdot 9$ & $5 \cdot 8$ & +2.5 & $1 \cdot 4$ & $7 \cdot 2$ & $3 \cdot 9$ & $+2 \cdot 2$ & $66 \cdot 1$ \\
\hline $47 \cdot 8$ & $7 \cdot 1$ & $5 \cdot 2$ & +2.4 & 4.8 & $+11 \cdot 2$ & +14.9 & $+21 \cdot 2$ & $7 \cdot 2$ & $68 \cdot 9$ \\
\hline $58 \cdot 4$ & -5.6 & -6.0 & -5.0 & $-6 \cdot 1$ & $\rightarrow 7 \cdot 1$ & -1.0 & -8.9 & $|-11 \cdot 7|$ & $71 \cdot 1$ \\
\hline $59 \cdot 1$ & $10 \cdot 7$ & +1.0 & 3.0 & +1.4 & $5 \cdot 3$ & $1 \cdot 2$ & 6.6 & $2 \cdot 7$ & 74.5 \\
\hline 64.7 & $7 \cdot 9$ & $-18 \cdot 0$ & $10 \cdot 7$ & -9.0 & $7 \cdot 9$ & $9 \cdot 9$ & +1.0 & $5 \cdot 9$ & $77 \cdot 3$ \\
\hline $70 \cdot 3$ & $2 \cdot 7$ & $7 \cdot 4$ & $1 \cdot 5$ & $9 \cdot 0$ & $6 \cdot 5$ & $1 \cdot 8$ & $5 \cdot 3$ & $2 \cdot 6$ & $80 \cdot 2$ \\
\hline $75 \cdot 9$ & $1 \cdot 2$ & $5 \cdot 2$ & $2 \cdot 2$ & $4 \cdot 7$ & +4.4 & $+\quad 1 \cdot 4$ & -2.2 & $4 \cdot 9$ & 83.0 \\
\hline $81 \cdot 6$ & $1 \cdot 6$ & +1.7 & 0.0 & $2 \cdot 0$ & $-20 \cdot 8$ & -0.0 & $11 \cdot 4$ & $1+1 \cdot 0$ & $85 \cdot 8$ \\
\hline $87 \cdot 2$ & 13.7 & 6.0 & 3.5 & $5 \cdot 6$ & $+2 \cdot 1$ & $|+11 \cdot 0|$ & $4 \cdot \mathrm{Cl}$ & 9.51 & $88 \cdot 6$ \\
\hline
\end{tabular}


Table of real Errors.

\begin{tabular}{|c|c|c|c|c|c|c|c|c|c|}
\hline $\begin{array}{l}\text { Name of } \\
\text { the Dot. }\end{array}$ & 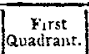 & $\left|\begin{array}{c}\text { Second } \\
\text { Quddran: }\end{array}\right|$ & $\begin{array}{c}\text { Third } \\
\text { uuatrant. }\end{array}$ & $\left|\begin{array}{c}\text { Foutth } \\
\text { Quadrant. }\end{array}\right|$ & 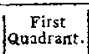 & $\begin{array}{c}\text { second } \\
\text { Quadi ant. }\end{array}$ & $\mid \begin{array}{c}\text { Thidd } \\
\text { Quadrant. }\end{array}$ & $\begin{array}{l}\text { roumh } \\
\text { guadrant. }\end{array}$ & $\begin{array}{l}y_{1 m e} \text { of } \\
\text { the Dot. }\end{array}$ \\
\hline$\stackrel{\circ}{0} 0$ & 0.0 & +8.8 & & +14.4 & -16.9 & -8.0 & -13.4 & $-22 \cdot 4$ & $\stackrel{0}{45} .0$ \\
\hline 7.4 & -4.8 & -0.6 & $16 \cdot 0$ & $5 \cdot 9$ & $8 \cdot 7$ & $5 \cdot 5$ & 9.7 & $16 \cdot 1$ & $46 \cdot 4$ \\
\hline $2 \cdot 8$ & $10 \cdot 2$ & $9-3$ & 24.0 & -2.9 & $14 \cdot 3$ & $9 \cdot 6$ & $17 \cdot 4$ & $22 \cdot 3$ & $47 \cdot 8$ \\
\hline $4 \cdot 2$ & $15 \cdot 8$ & $15 \cdot 1$ & $28 \cdot 3$ & $12 \cdot 8$ & $22 \cdot 3$ & $17 \cdot 9$ & $19 \cdot 9$ & 33.8 & $49 \cdot 3$ \\
\hline $5 \cdot 6$ & $13 \cdot 7$ & 12.5 & $23 \cdot 3$ & $16 \cdot 1$ & 26.0 & $21 \cdot 6$ & $26 \cdot 7$ & $31 \cdot 0$ & $50 \cdot 6$ \\
\hline $7 \cdot 0$ & $15 \cdot 9$ & 16.8 & $28 \cdot 7$ & 19.4 & $25 \cdot 5$ & 26.0 & 23.6 & 28.9 & $52 \cdot 0$ \\
\hline $8 \cdot 4$ & $17 \cdot 6$ & $19 \cdot 6$ & $32 \cdot 0$ & $27 \cdot 0$ & $32 \cdot 0$ & $27 \cdot 8$ & $30 \cdot 3$ & $38 \cdot 3$ & $5 S \cdot 4$ \\
\hline $9 \cdot 8$ & $21 \cdot 4$ & $16 \cdot 1$ & 35.5 & $30 \cdot 7$ & $84 \cdot 0$ & $27 \cdot 3$ & $29 \cdot 1$ & $35 \cdot 2$ & $54 \cdot 8$ \\
\hline 11.2 & $21 \cdot 6$ & $16 \cdot 7$ & 31.5 & 26.5 & $20 \cdot 8$ & $22 \cdot 1$ & $24 \cdot 0$ & $32 \cdot 6$ & $56 \cdot 2$ \\
\hline $12 \cdot 7$ & $27 \cdot 9$ & $21 \cdot 6$ & $32 \cdot 2$ & $28 \cdot 6$ & $29 \cdot 6$ & $24 \cdot 5$ & $29 \cdot 7$ & 29.8 & $57 \cdot 7$ \\
\hline $14 \cdot 1$ & $31 \cdot 1$ & $26 \cdot 3$ & $37 \cdot 5$ & $34 \cdot 4$ & $33 \cdot 7$ & $17 \cdot 7$ & $27 \cdot z$ & $24 \cdot 6$ & $59 \cdot]$ \\
\hline $15 \cdot 5$ & $28 \cdot 5$ & $22 \cdot ?$ & $30 \cdot 2$ & $26 \cdot 8$ & $30 \cdot 2$ & $15 \cdot 6$ & $29 \cdot 3$ & 20.5 & $60 \cdot 5$ \\
\hline $16 \cdot 9$ & $27 \cdot 3$ & $20 \cdot 5$ & $32 \cdot 4$ & $32 \cdot 7$ & $19 \cdot 2$ & $15 \cdot 3$ & $24 \cdot 1$ & $19 \cdot 4$ & 61.9 \\
\hline $18 \cdot 3$ & $29 \cdot 9$ & $18 \cdot 2$ & $24 \cdot 2$ & $25 \cdot 7$ & $21 \cdot 5$ & $14 \cdot 6$ & 18.8 & $23 \cdot 7$ & 63.3 \\
\hline $19 \cdot 7$ & $20 \cdot 2$ & $13 \cdot 5$ & $20 \cdot 6$ & $22 \cdot 2$ & $19 \cdot 0$ & $21 \cdot 5$ & $22 \cdot 4$ & $17 \cdot 4$ & 64.7 \\
\hline $21 \cdot 1$ & $22 \cdot 4$ & $5 \cdot 9$ & $22 \cdot 1$ & $24 \cdot 0$ & 18.8 & $19 \cdot 9$ & $22 \cdot 8$ & $17 \cdot 1$ & $\cdot 66 \cdot 1$ \\
\hline 22.5 & $10 \cdot 0$ & $1 \cdot 8$ & $10 \cdot 9$ & $6 \cdot 7$ & 5.0 & +8.2 & +0.7 & +2.5 & $67 \cdot 5$ \\
\hline $23 \cdot 9$ & 8.8 & $12 \cdot 2$ & $16 \cdot 0$ & 14.9 & $9 \cdot 8$ & -2.8 & $-2 \cdot 5$ & -13.0 & $68 \cdot 9$ \\
\hline $25 \cdot 3$ & $19 \cdot 8$ & $15 \cdot 5$ & $20 \cdot 2$ & $24 \cdot 0$ & $15 \cdot 7$ & $10 \cdot 2$ & 157 & $19 \cdot 2$ & $70 \cdot 3$ \\
\hline $26 \cdot 7$ & $21 \cdot 7$ & $16 \cdot 1$ & $20 \cdot 0$ & $33 \cdot 0$ & $21 \cdot 9$ & $7 \cdot 0$ & $21 \cdot 8$ & $25 \cdot 8$ & $71 \cdot 7$ \\
\hline $28 \cdot 1$ & $22 \cdot 1$ & $12 \cdot 8$ & $23 \cdot 8$ & 36.4 & 23.0 & 13.9 & $25 \cdot 1$ & 23.0 & 73.1 \\
\hline 29.5 & $17 \cdot 1$ & $15 \cdot 8$ & 28.9 & $35 \cdot 0$ & 27.1 & $14 \cdot 3$ & $25 \cdot 3$ & $26 \cdot 8$ & $74 \cdot 5$ \\
\hline $30 \cdot 9$ & $22 \cdot 1$ & $18 \cdot 0$ & $31 \cdot 4$ & $37 \cdot 0$ & $26 \cdot 6$ & $20 \cdot 1$ & $26 \cdot 6$ & 30.7 & $75 \cdot 9$ \\
\hline $32 \cdot 3$ & $24 \cdot 7$ & $19 \cdot 3$ & $33 \cdot 3$ & $37 \cdot 7$ & $33 \cdot 3$ & $21 \cdot 1$ & $22 \cdot 7$ & $31 \cdot 1$ & $77 \cdot 3$ \\
\hline 93.7 & $17 \cdot 4$ & $9 \cdot 1$ & $25 \cdot 1$ & $37 \cdot 6$ & $27 \cdot 9$ & 16.0 & $23 \cdot 8$ & $29 \cdot 1$ & 78.7 \\
\hline $35 \cdot 2$ & $22 \cdot 7$ & $8 \cdot 0$ & $25 \cdot I$ & 95.7 & $35 \cdot 5$ & 14.5 & 18.5 & $28 \cdot 7$ & $80 \cdot 2^{2}$ \\
\hline $36 \cdot 6$ & $27 \cdot 3$ & $11 \cdot 9$ & $27 \cdot 4$ & $41 \cdot 8$ & $29 \cdot 3$ & $9 \cdot 0$ & $22 \cdot 4$ & $27 \cdot 9$ & 816 \\
\hline $38 \cdot 0$ & $26 \cdot 5$ & $15 \cdot 6$ & $26 \cdot 9$ & $40 \cdot 6$ & $21 \cdot 0$ & $6 \cdot 6$ & 17.5 & $21 \cdot 4$ & 830 \\
\hline $39 \cdot 4$ & $26 \cdot 4$ & $16 \cdot 7$ & 24.8 & 431 & 27.5 & $5 \cdot 4$ & $21 \cdot 0$ & $21 \cdot 6$ & $84 \cdot 4$ \\
\hline 40.8 & $25 \cdot 4$ & 7.2 & $25 \cdot 1$ & $33 \cdot 6$ & $31 \cdot 0$ & $7 \cdot 9$ & $15 \cdot 4$ & $12 \cdot 6$ & $85 \cdot 8$ \\
\hline $42 \cdot 2$ & 18.5 & $10 \cdot 4$ & $24 \cdot 7$ & 30,2 & $23 \cdot 0$ & $0 . i$ & $6 \cdot 8$ & $5 \cdot \stackrel{4}{2}$ & $87 \cdot 1$ \\
\hline $49 \cdot 6$ & $16 \cdot 3$ & 10.0 & $24 \cdot 6$ & 31.7 & $16 \cdot 3$ & $3 \cdot 7$ & $15 \cdot 9$ & $6 \cdot 4$ & $88 \cdot 6$ \\
\hline $45 \cdot 0$ & 16.9 & 8.0 & $J 3 \cdot 0$ & $22 \cdot 4$ & +8.8 & $6 \cdot 9$ & $1+14.4$ & $0 \cdot 0:$ & 90.0 \\
\hline
\end{tabular}

